\title{
Myopia and Digit Ratio in Medical College Students - A Gender Based Evidence
}

\author{
Dr. Shumaila Humayun, \\ Community Medicine Deptt, \\ Foundation University Medical College, Islamabad \\ Syed Ali Hasan, \\ Haider Aizaz, \\ Tashfeen Farooq, \\ Israh Manzoor, \\ Javeria Jameel, \\ Jazla Siddiqua, \\ Students of 4th year MBBS, \\ Foundation University Medical College.(FUMC), Islamabad
}

Doi: 10.19044/esj.2018.v14n36p150 URL:http://dx.doi.org/10.19044/esj.2018.v14n36p150

\begin{abstract}
Objectives: To measure digit ratios in male and female medical students and compare their relationship with myopia. Study Design: crosssectional study. Place and duration of study: February to September 2016, at Foundation University Medical College. Materials and methodology: Convenient sampling technique was used and 150 students filled a structured questionnaire after giving written informed consent. Students with past history of eye surgery or trauma were excluded. Prescriptions of students were noted for the myopia, and digit lengths measured on a computer via Adobe Photoshop after taking photographs of both hands on scanner and analysed using SPSS version 21. Results: A total of 141 completed questionnaires revealed that 90 students were myopic (63.8\%), of which 39 were males (27.7\%) and 51 females (36.2\%). Myopic males had larger digit ratios (Right, left and mean) as compared to non-myopic males, whereas myopic females had lower digit ratios as compared to non-myopic females. However a 2 tailed t- test showed significance between right hand digit ratio of male myopes and non-myopes only. Females showed no significance. Pearson's correlation showed positive correlation of digit ratios and refractive errors in males but negative in females, however it was not significant. Conclusion: Myopia was prevalent in majority of student sample. There were significant differences between the digit ratios of males and females,
\end{abstract}


and right hand digit ratios of males were significantly higher in myopes compared to non myopes. However, Pearson's correlation was not found significant.

Keywords: Cross sectional,digit ratio,myopia, prevalence

\section{Introduction}

Myopia is an eye disorder in which the eyes focus images in front of the retina, resulting in reduced visual acuity. In myopia, the axial length of the eyeball is too long or the shape of the lens and cornea is abnormal, according to PubMed Health. Myopia is a refractive error that is one of the major causes of blindness (Bourne et al., 2013) and has many complications including increased susceptibility to the formation of cataracts, glaucoma, myopic macular degeneration, choroidal neovascularization, and retinal detachment ( Saw et al., 2005). In addition to the ocular abnormalities, the economic burden of myopia is also high with a mean cost of USD \$709 per person per year in adults (Zheng et al., 2013). Early diagnosis of pathological myopia is crucial.

According to the Global data on visual impairments (2010) by WHO, there are about 285 million people visually impaired, 39 million of them are blind and 246 million have low vision $(<6 / 18>/ 3 / 60)$. According to a study in Taiwan myopic macular degeneration was among the leading causes of blindness reaching $12.5 \%$ in the Shihpai Eye Study (Hasu et al., 2004).

In India, prevalence of myopia in people aged 40 and above was reported to be $34.6 \%$, and in Bangladesh it was reported to be $23.8 \%$ over the age of 30 years with myopia defined as at least - 0.5 D (Pan, Ramamuthi and Saw, 2012). In Pakistan, the prevalence of myopia is about $36.5 \%$ which is higher when compared to the western countries (Castano et al., 2003 and Suzuki et al., 2001).

Steroid receptors have been found in ocular tissues and are thought to be responsible for growth and development of the eyeball. Generally, there is a high prevalence and severity of myopia in females ( Gong et al., 2015). Gong especially in those with increased levels of testosterone. Moreover, estrogen has been shown to influence some properties of the cornea (Zubaty and Pillunat, 2017) including corneal thickness that varies with menstrual cycles (Guifrre et al., 2007) and corneal curvature that changes in pregnancy.

Digit ratio is the ratio of the 2 nd to the 4 th finger length. It is sexually dimorphic, and is determined at the 14th week of gestation by pre-natal testosterone levels, from the 8th week to mid gestation (Honkopet et al, 2007). There are steroid receptors present in the phalanges, with more androgen receptors $(A R)$ on the $4^{\text {th }}$ digit, compared to the $2^{\text {nd }}$ digit (Zheng and Cohn, 2011), which may explain the basis of the sexual dimorphism in digit ratios, 
related to the relative levels of androgens and estrogens; Testosterone upregulates genes responsible for chondrocyte proliferation, and hence the $4^{\text {th }}$ digit length increases, resulting in decreased digit ratio, whereas estrogens have the opposite effect, decreasing chondrocyte proliferation on the $4^{\text {th }}$ digit.

Differentiation of gonads, fingers and toes has also been shown to be under the control of HOX genes (Manning, Callowand and Bundered, 2011); HOX may influence digit length as well as gonadal testosterone too, which may independently influence digit lengths.HOX genes have also been shown to be regulated by hormones, including sex steroids (Daftary and Taylor, 2006). Since digit ratio is sexually dimorphic it can be argued that digit ratio can be related to other dimorphic traits as was done by Manning et al (2002).

Previously, a study on the gender difference of digit ratio in the local population has been done in Pakistan (Hussain, Khan and Ali, 2002), but not of its correlation with myopia. Also the finger lengths were measured manually, however it has been shown that computer assisted measurements are superior (Allaway et al. 2009).

The purpose of this study is to determine the prevalence of myopia in study population and to find a relation between myopia and digit ratio, as researchers are still keen to see if there exists one. This study has been done only once i.e. the Chennai study in $2014^{20}$, to the best of our knowledge and a negative association between digit ratio and myopia was found. The association can be used to screen young children for digit ratios and hence their susceptibility to myopia, and high risk population could be advised regular ophthalmological visits. This research will add to the body of knowledge and pave pathways for such studies in the future in an effort to prevent blindness due to myopia, by early detection of high risk cases, and hence early treatment.

\section{Materials and Methods}

This cross-sectional study was conducted at Foundation University Medical College DHA-1, Islamabad, from February to September 2016.Convenient sampling technique was used and a total of 150 male and female students participated in the study.Myopia was taken as a refractive error of at least $-0.5 \mathrm{D}$. Students with a past history of eye surgery or trauma to the eye were not included.

The data was collected by using a pretested structured questionnaire filled by all the respondents after taking written informed consent. Prescriptions of the students were noted and the means of both eyes were taken, and written on the questionnaires. Digit ratios were obtained by first using a scanner to scan a $30 \mathrm{~cm}$ scale at 300 dpi resolution. The image was then imported to adobe Photoshop. Next, the number of pixels within $30 \mathrm{~cm}$ of the scale was measured using the ruler tool. With the ruler tool calibrated, 
finger lengths were measured from the bottom crease to the top of the finger. Changing contrast in blurred images revealed the finger margins and crease. Digit ratio was calculated as 2D:4D (Index finger: Ring finger) ratio. Complete data of 141 students, 72 females and 69 males,was entered in computer and SPSS version 21 was used for analysis.

\section{Results}

The study population included medical students, aged 18 to 25 years, with a mean age of 21.25 years. Among them,123 students were urban residents and 18 were from rural areas. Students from classes First through Final year MBBS participated in the study, 69 being males and 72 females.

Out of a total of 141 students, 90 were myopes $(63.8 \%)$ of which 39 were males $(27.7 \%)$ and 51 were females (36.2\%). Non-myopes were 51 (36.2 $\%)$ of which 30 were males $(21.3 \%)$ and 21 were females $(14.9 \%)$.

\begin{tabular}{|c|c|c|c|c|}
\hline \multicolumn{4}{|c|}{ Table I: Myopes and non myopes : Both genders } & \\
\hline & & & gender & gender \\
\hline & & & male & female \\
\hline \multirow{8}{*}{$\begin{array}{l}\text { group of myopes and non } \\
\text { myopes }\end{array}$} & \multirow{4}{*}{$\begin{array}{l}\text { Non } \\
\text { myopes }\end{array}$} & Count & 30 & 21 \\
\hline & & $\begin{array}{l}\% \text { within group of myopes and non } \\
\text { myopes }\end{array}$ & $58.8 \%$ & $41.2 \%$ \\
\hline & & $\%$ within gender & $43.5 \%$ & $29.2 \%$ \\
\hline & & $\%$ of Total & $21.3 \%$ & $14.9 \%$ \\
\hline & \multirow{4}{*}{ myopes } & Count & 39 & $51 \%$ \\
\hline & & $\begin{array}{l}\% \text { within group of myopes and non } \\
\text { myopes }\end{array}$ & $43.3 \%$ & $56.7 \%$ \\
\hline & & $\%$ within gender & $56.5 \%$ & $70.8 \%$ \\
\hline & & $\%$ of Total & $27.7 \%$ & $36.2 \%$ \\
\hline \multirow{4}{*}{ Total } & & Count & 69 & 72 \\
\hline & & $\begin{array}{l}\% \text { within group of myopes and non } \\
\text { myopes }\end{array}$ & $48.9 \%$ & $51.1 \%$ \\
\hline & & $\%$ within gender & $100.0 \%$ & $100.0 \%$ \\
\hline & & $\%$ of Total & $48.9 \%$ & $51.1 \%$ \\
\hline
\end{tabular}

Right hand $2^{\text {nd }}$ digit length (R2D) was found to be (Males: $7.57+/-$ $0.50 \mathrm{~cm}$ and Females: $6.94+/-0.41 \mathrm{~cm})$. Right hand $4^{\text {th }}$ digit length $(\mathrm{R} 4 \mathrm{D})$ was found to be (Males: $7.85+/-0.53 \mathrm{~cm}$ and Females: $7.08+/-0.47 \mathrm{~cm}$ ). Finally, right hand mean digit ratio was found to be (Males: $0.964+/-0.03 \mathrm{~cm}$ and Females: $0.978+/-0.03 \mathrm{~cm})$.Left hand $2^{\text {nd }}$ digit length (L2D) was found to be (Males: $7.57+/-0.53 \mathrm{~cm}$ and Females: $6.89+/-0.45 \mathrm{~cm}$ ). Left hand $4^{\text {th }}$ digit (L4D) was found to be (Males: $7.86+/-0.54 \mathrm{~cm}$ and Females: $7.02+/-$ $0.44 \mathrm{~cm}$ ).Digit ratio of left hand was found to be (Males: $0.962+/-0.03$ and 
Females: $0.979+/-0.03 \mathrm{~cm}$ ).Mean digit ratios were (Males: $0.963+/-0.029$ cm and Females: $0.979+/-0.03$ ).

\begin{tabular}{|l|l|r|r|r|r|}
\hline \multicolumn{7}{|c|}{ Table II : Finger lengths } \\
\hline \multirow{2}{*}{ gender } & $\begin{array}{c}\text { measurement of } \\
\text { right hand } \\
\text { second digit }\end{array}$ & $\begin{array}{c}\text { measurement of } \\
\text { right hand } \\
\text { fourth digit }\end{array}$ & $\begin{array}{c}\text { measurement of } \\
\text { left hand second } \\
\text { digit }\end{array}$ & $\begin{array}{r}\text { measurement of } \\
\text { left hand fourth } \\
\text { digit }\end{array}$ \\
\hline \multirow{2}{*}{ male } & Mean & 7.5738 & 7.8526 & 7.5762 & 7.8662 \\
\cline { 2 - 7 } female & Mean & 69 & 69 & 69 & 69 \\
\cline { 2 - 7 } & N & 6.9457 & 7.0843 & 6.8931 & 7.0289 \\
\hline \multirow{2}{*}{ Total } & Mean & 72 & 72 & 72 & 72 \\
\cline { 2 - 7 } & N & 7.2530 & 7.4603 & 7.2274 & 7.4387 \\
\hline
\end{tabular}

Myopic males were found to have higher digit ratios (Right, left and mean) as compared to non-myopic males whereas myopic females had lower digit ratios (Right, left and mean) as compared to non-myopic females. However a 2 tailed t- test showed significance between right hand digit ratio of male myopes and non-myopes only. Females showed no significance.

\begin{tabular}{|l|l|r|r|}
\hline \multicolumn{4}{|c|}{ Table IIII: Digit ratios } \\
\hline \multirow{2}{*}{ Gender } & $\begin{array}{r}\text { ratio of right hand 2nd } \\
\text { and 4th digit }\end{array}$ & ratio of left hand 2nd and 4th digit \\
\hline \multirow{3}{*}{ male } & Mean & .96496 & .96201 \\
\cline { 2 - 5 } & $\mathrm{N}$ & 69 & 69 \\
\cline { 2 - 5 } & Std. Deviation & .031835 & .032319 \\
\hline \multirow{3}{*}{ female } & Mean & .97880 & .97931 \\
\cline { 2 - 5 } & $\mathrm{N}$ & 72 & 72 \\
\cline { 2 - 5 } & Std. Deviation & .032010 & .035683 \\
\hline \multirow{3}{*}{ Total } & Mean & .97203 & .97085 \\
\cline { 2 - 5 } & N & 141 & 141 \\
\cline { 2 - 5 } & Std. Deviation & .032560 & .035048 \\
\hline
\end{tabular}

Finally, Pearson's correlation was used to find association of digit ratios with refractive errors. The result showed positive correlation in males but negative in females, however it was not significant(at p-value <0.05).

\begin{tabular}{|c|c|c|}
\hline \multicolumn{3}{|c|}{ Table IV: Independent sample t-test for gender-wise difference in digit-ratios } \\
\hline & Gender & Sig. (2-tailed) \\
\hline \multirow{6}{*}{ male } & \multirow{2}{*}{ ratio of right hand 2 nd and 4 th digit } & .041 \\
\hline & & .037 \\
\hline & \multirow{2}{*}{ ratio of left hand 2 nd and 4 th digit } & .656 \\
\hline & & .651 \\
\hline & \multirow{2}{*}{ Mean of ratios } & .181 \\
\hline & & .175 \\
\hline \multirow{6}{*}{ female } & \multirow{2}{*}{ ratio of right hand 2 nd and 4 th digit } & .288 \\
\hline & & .326 \\
\hline & \multirow{2}{*}{ ratio of left hand 2 nd and 4 th digit } & .771 \\
\hline & & .775 \\
\hline & \multirow{2}{*}{ Mean of ratios } & .487 \\
\hline & & .510 \\
\hline
\end{tabular}


Table V : Pearson's correlation : digit ratio with myopia

\begin{tabular}{|c|c|c|c|}
\hline & & FEMALE & MALE \\
\hline \multirow{3}{*}{ ratio of right hand 2 nd and 4 th digit } & Pearson Correlation & -.098 & .181 \\
\hline & Sig. (2-tailed) & .415 & .137 \\
\hline & $\mathrm{N}$ & 72 & 69 \\
\hline \multirow[b]{2}{*}{ ratio of left hand 2 nd and 4 th digit } & Pearson Correlation & -.036 & .150 \\
\hline & Sig. (2-tailed) & .763 & .218 \\
\hline \multirow[t]{2}{*}{ Mean of ratios } & Pearson Correlation & -.069 & .180 \\
\hline & Sig.(2-tailed) & .564 & .139 \\
\hline
\end{tabular}

\section{Discussion}

The prevalence of myopia in our study was $63.8 \%$, which was more in females (Males: 56.5\% and Females: $70.8 \%$ ).In the Chennai study (Krishnakumar, 2014), prevalence of myopia came out to be 54\% (Males: 54.3\% and Females: $53.7 \%$ by gender).A Turkish study reported a prevalence of $32.9 \%$ among medical students, with myopia defined as spherical equivalent of at least $-0.75 \mathrm{D}$ (Onal et al, 2007). However, our study took myopia as at least $-0.5 \mathrm{D}$, so that could account for the difference with respect to the Turkish study. Also, in both studies there was almost no gender wise difference in the prevalence, contrary to our study. Prevalence of myopia in our study was significantly higher than the reported crude prevalence of myopia from the national blindness and visual impairment survey published in 2006 (36.5\%) done on 16,507 adults aged over 30 years age. This could be due to the more advanced education of medical students compared to the general population, which has been linked to myopia. However unlike the Chennai study, the refractive errors in this study were taken from means of the prescription presented at the time of study.

In our study, it was evident that males had a lower digit ratio compared to females, a finding which has been approved by previous studies.Digit ratios were lower in myopic females than non-myopic females, whereas myopic males had a larger ratio than non-myopic males. However, only right hand ratio of male myopes and non-myopes showed a significant difference at $\mathrm{p}<$ 0.05 . The Chennai study, reported digit ratios being lower in myopes than non-myopes of both genders, and no difference in the digit ratios of males and females, unlike our study.

A local study done previously in Islamabad and Rawalpindi, measured digit ratios by calipers, but not by software assisted measurements as done in this study. In that study, the data was collected for 50 males and 50 females and showed significant differences in digit ratios between males and females at $\mathrm{p}<0.01$.Our study on the other hand showed right hand ratio difference at $\mathrm{p}<0.05$, and left hand and mean ratio difference at $\mathrm{p}<0.01$. 
Steroid receptors are known to be present in ocular tissues and affect corneal thickness as well as scleral remodeling. This is evident from corneal thickness changes during menstrual cycles of females ${ }^{16}$ and during pregnancy 17. Also, myopia progression is seen to increase around puberty. Females generally have faster myopia progression and prevalence, and especially those having relatively higher testosterone levels. There is also evidence linking myopia and a higher IQ level, adjusted for time spent reading (Verma and Verma, 2015). Testosterone has been related to brain lateralization with increased development of right brain, hence better spatial and mathematical ability. Digit ratio has also been shown to be negatively related to brain lateralization (Kalmady, 2013). Hence it stands to reason that a common factor like testosterone could influence eyeball and brain development and digit ratio.

Lastly, Pearson's correlation was used to find any association between myopia and digit ratio and it showed a negative association of myopia and digit ratio for females only, however the result was not significant. Males showed a positive correlation which was not significant as well. Nevertheless, this conflicting correlation among males and females could be because of differences in polymorphisms of steroidogenesis enzymes and different gene activity in response to steroids among males and females. Whereas the Chennai study applied Spearman's correlation, and found significant differences in females only $(\mathrm{P}<0.01)$.

\section{Conclusion}

The study concluded that prevalence of myopia was high among medical college students. There were significant differences between the digit ratios of males and females, and right hand digit ratios of males were significantly higher in myopes compared to non myopes. Study should be extended on a larger sample size with probability sampling in order to generate a data base to help future researchers.

\section{Statement of Novelty}

The gender difference of digit ratios has been highlighted and researched in various countries of the world but extensive literature survey indicates no significant study conducted in Pakistan comparing the relationship of myopia and digit ratio. The study fills an identified gap in the body of knowledge and proves to be a contribution to the domain of public health.

\section{Conflict of Interest}

This study has no conflict of interest to be declared by the authors. 


\section{Research Ethics Committee}

The approval of the research ethics committee of the medical college was taken prior to the study.

\section{References:}

1. Bourne RR, Stevens GA, White RA, Smith JL, Flaxman SR, Price H, et al. Causes of vision loss worldwide, 1990-2010: a systematic analysis. The Lancet Global Health. 2013 Dec 31;1(6): 339-49.

2. Saw SM, Gazzard G, Shih-Yen EC, Chua WH. Myopia and associated pathological complications. Ophthalmic and Physiological Optics. 2005 Sep 1;25(5):381-91.

3. Zheng YF, Pan CW, Chay J, Wong TY, Finkelstein E, Saw SM. The Economic cost of myopia in adults aged over 40 years in Singapore. Cost of Myopia in Singapore. Investigative ophthalmology \& visual science. 2013 Nov 1;54(12):7532-7.

4. Hsu WM, Cheng CY, Liu JH, Tsai SY, Chou P. Prevalence and causes of visual impairment in an elderly Chinese population in Taiwan: the Shihpai Eye Study. Ophthalmology. 2004 Jan 31;111(1):62-9.

5. Pan C W, Ramamurthy D, Saw SM.Worldwide prevalence and risk factors for myopia.Ophthalmic and Physiological Optics.2012 Jan 1;32(1):3-16. DOI:10.1111/j.1475-1313.2011.00884.x

6. Jadoon MZ, Dineen B, Bourne RR, Shah SP, Khan MA, Johnson GJ, et al.Refractive errors in the adult Pakistani population: the national blindness and visual impairment survey. Invest Ophthalmol Vis Sci. 2006 Nov;47(11):4749-55

7. Marin-Castaño ME, Elliot SJ, Potier M, Karl M, Striker LJ, Striker $\mathrm{GE}$, et al. Regulation of estrogen receptors and MMP-2 expression by estrogens in human retinal pigment epithelium. Invest Ophthalmol Vis Sci 2003; 44:50-9.

8. Suzuki T, Kinoshita Y, Tachibana M, Matsushima Y, Kobayashi $\mathrm{Y}$, Adachi W, et al. Expression of sex steroid hormone receptors in human cornea. Curr Eye Res. 2001 Jan;22(1):28-33.

9. Gong JF, Xie HL, Mao XJ, Zhu XB, Xie ZK, Yang HH, et al. Relevant factors of estrogen changes of myopia in adolescent females. Chinese medical journal. 2015 Mar 1;128(5):659.

10. Mo Y,Wang MF, Zhou LL.Risk factor analysis of 167 patients with high myopia.International journal of ophthalmology.2010;3(1):80

11. Spoerl E, Zubaty V, Raiskup-Wolf F, Pillunat LE. Oestrogen-induced changes in biomechanics in the cornea as a possible reason for keratectasia. Br J Ophthalmol. 2007; 91:1547-50. [PMID: 17591666] 
12. Giuffrè G, Di RL, Fiorino F, Bubella DM, Lodato G. Variations in central corneal thickness during the menstrual cycle in women. Cornea. 2007; 26:144-6. [PMID: 17251801]

13. Hönekopp J, Bartholdt L, Beier L, Liebert A. Second to fourth digit length ratio (2D: 4D) and adult sex hormone levels: new data and a meta-analytic review. Psychoneuroendocrinology. 2007 May 31;32(4):313-21.

14. Zheng Z, Cohn MJ. Developmental basis of sexually dimorphic digit ratios. Proceedings of the National Academy of Sciences. 2011 Sep 27;108(39):16289-94.

15. Manning JT, Callow M, Bundred PE. Finger and toe ratios in humans and mice: implications for the aetiology of diseases influenced by HOX genes. Medical Hypotheses. 2003 Mar 31;60(3):340-3.

16. Daftary GS, Taylor HS. Endocrine regulation of HOX genes. Endocrine reviews. 2006 Jun;27(4):331-55.

17. Manning JT. Digit ratio: A pointer to fertility, behavior, and health. Rutgers University Press; 2002.DOI:10.1038/sj.hdy.6800151

18. Hussain S M, Khan S A, Ali S M, Hussain S A. The gender difference of $2^{\text {nd }}$ to $4^{\text {th }}$ digit length and length ratio $(2 \mathrm{D}: 4 \mathrm{D})$ in local population.FUMJ Vol-1-No-1-Jan-Jun-2014.

19. Allaway HC, Bloski TG, Pierson RA, Lujan ME. Digit ratios (2D: 4D) determined by computer-assisted analysis are more reliable than those using physical measurements, photocopies, and printed scans. American Journal of Human Biology. 2009 May 1;21(3):365-70.

20. Krishnakumar M, Atheeshwar S, Chandrasekar MD. Myopia and digit ratio in medical college students. PloS one. 2014 Feb 21;9(2):e89800. DOI:10.1371/journal.pone.0089800

21. Verma A, Verma A. A Novel Review of the Evidence Linking Myopia and High Intelligence. Journal of ophthalmology. 2015 Jan 11;2015.

22. Kalmady SV, Agarwal SM, Shivakumar V, Jose D, Venkatasubramanian G, Reddy YJ. Revisiting Geschwind's hypothesis on brain lateralisation: A functional MRI study of digit ratio (2D: 4D) and sex interaction effects on spatial working memory. Laterality: Asymmetries of body, brain and cognition. 2013 Sep 1;18(5):625-40.

23. Onal S, Toker E, Akingol Z, Arslan G, Ertan S, Turan C, et al. Refractive errors of medical students in Turkey: one year follow-up of refraction and biometry. Optometry \& Vision Science. 2007 Mar $1 ; 84(3): 175-80$.

24. Mirshahi A, Ponto KA, Hoehn R, Zwiener I, Zeller T, Lackner K, et al. Myopia and level of education: results from the Gutenberg Health Study. Ophthalmology. 2014 Oct 31;121(10):2047-52 